Original Research Article

\title{
Observational study of drug use pattern in indoor patients suffering from major depression admitted in psychiatry department of tertiary care teaching hospital
}

\author{
Vaishali Thakare ${ }^{1}$, Lily Dubey ${ }^{2 *}$
}

${ }^{1}$ Department of Pharmacology, Dr. D.Y. Patil Medical College, Navi-Mumbai, Maharashtra, India

${ }^{2}$ Department of Pharmacology, Bundelkand Medical College, Sagar, Madhya Pradesh, India

Received: 09 July 2018 Accepted: 04 August 2018

*Correspondence to:

Dr. Lily Dubey,

Email: lilydubeyg@gmail.com

Copyright: (C) the author(s), publisher and licensee Medip Academy. This is an openaccess article distributed under the terms of the Creative Commons Attribution NonCommercial License, which permits unrestricted noncommercial use, distribution, and reproduction in any medium, provided the original work is properly cited.

\begin{abstract}
Background: Mental illness is associated with high levels of health service utilization and associated costs. India is among one of the countries with the highest number of people suffering from depression. The data on antidepressant drug utilization in India is sparse. Hence, we planned to analyse the drug use pattern in patients of major depression as per the WHO recommended indicators of drug use.
\end{abstract}

Methods: This prospective observational study was done to analyze the prescription pattern of hospital psychiatrist in indoor major depression patients. All the patients admitted in psychiatry indoor patient department (I. P. D.) of Dr. D. Y. Patil Hospital, Navi Mumbai were included.

Results: Data of 97 patients was analysed. $55.67 \%$ of the cases were from the age group 31-50 years. Total number of antidepressants prescribed was $102(36.82 \%)$. Out of antidepressant agents, Selective Serotonin Reuptake Inhibitors (SSRIs) were the most commonly prescribed drugs $70(68.62 \%)$. The most commonly prescribed antidepressant was Sertraline in 35 (34.3\%).

Conclusions: The findings of our study were similar to those of other studies conducted to evaluate the use of antidepressants.

Keywords: Depression, Off-label, Prescribing pattern, Polypharmacy

\section{INTRODUCTION}

Psychiatric disorders form an important public health priority. Out of the top ten health conditions contributing to the Disability Adjusted Life Years, four are psychiatric disorders. ${ }^{1-3}$ Mental illness is associated with high levels of health service utilization and associated costs. In developing countries these costs are mostly paid by the patient. ${ }^{4}$ Depression is becoming important health problem worldwide because of its relatively high lifetime prevalence, significant disability, suffering, dysfunction and economic burden caused by it. India is among one of the countries with the highest number of people suffering from depression. Antidepressant prescribing patterns have changed globally over the last few years, with conventional drugs like Tricyclic antidepressants and Monoamine oxidase inhibitors being gradually replaced by selective serotonin reuptake inhibitors (SSRI) and novel antidepressants. ${ }^{5}$ The prevalence of antidepressant usage in the community is rising. ${ }^{6}$ Antidepressant polypharmacy is common and, on the rise, but very few studies have addressed this problem. Many studies have pointed out the frequent lack of concordance between psychiatric diagnoses and the prescribed psychotropic medications i. 
e. their off label use. ${ }^{7,8}$ The data on antidepressant drug utilization in India is sparse. Hence, authors planned to analyse the drug use pattern in patients of major depression as per WHO recommended indicators of drug use.

The aim of this study was to evaluate drug utilization pattern in patients of Major depression in the indoor psychiatry department of a tertiary care teaching hospital.

\section{Primary objective}

To observe the prescribing pattern in a patient of major depression as per WHO drug use indicators.

\section{Secondary objective}

To evaluate the off-label use, concomitant medications and antidepressant poly-pharmacy.

\section{METHODS}

This prospective observational study was done in Psychiatry IPD of Dr. D. Y. Patil Hospital and Research centre, Nerul, Navi-Mumbai (India). The duration of the study was around one year starting from August 2013 to July 2014. All the admitted patients were screened for fulfilment of inclusion criteria A total of 97 patients were enrolled in the study after approval from the Institutional Ethics Committee. Written informed consent from legally accepted representative (LAR) was obtained. Since the study population comprises of subject belonging to vulnerable population, special care was taken to obtain informed consent. The patient information was recorded on a predesigned case record form (CRF). The demographic, disease and drug profile of all the study subjects was recorded. Information regarding the antidepressants being prescribed and use of concomitant medications was noted.

The following steps were taken to maintain the subject confidentiality. Identification of patients by hospital number and not by name, case records were assessed by investigator in the ward and the patient details were not divulged to anyone outside the hospital. Data collected on the CRF was later transcribed on a Microsoft excel file. The data so obtained was analysed using SPSS version 16 and results were expressed in numbers and percentages (\%). Microsoft Word and Excel were used to generate graphs and tables.

\section{Inclusion criteria}

All diagnosed cases of Major depression (DSVM IV criteria and ICD 10) above 18 years of age belonging to either gender admitted in the Psychiatry indoor patient department (IPD) of Dr. D. Y. Patil Hospital and Research centre, Nerul, Navi-Mumbai (India) and who were on treatment with psychotropic drugs by the treating psychiatrist. Also, from whom signed informed consent form from legally accepted representative was available.

\section{RESULTS}

Data from 97 patients was analysed. Amongst the total study subjects $42(43.3 \%)$ were males and $55(56.7 \%)$ were females. The majority of the major depression cases were females. The age of the study subjects was further divided into three categories, 18-30 years, 31- 50 years and greater than 50 years of age. Details of age wise distribution is given in Table 1. This suggests that our study mainly comprised of study subjects belonging to the middle age group subjects that is $31-50$ years.

Table 1: Demographic and age wise distribution in major depression.

\begin{tabular}{|lllll|}
\hline \multirow{2}{*}{ Age } & $\mathbf{1 8 - 3 0}$ & $\mathbf{3 1 -}$ & $\mathbf{> 5 0}$ & Total \\
& yearsin & $\mathbf{5 0 Y e a r s}$ & years & \\
\hline \multirow{2}{*}{$\mathrm{n}(\%)$} & 32 & 54 & 11 & 97 \\
& $(32.98 \%)$ & $(55.67 \%)$ & $(11.34 \%)$ & $(22.76 \%)$ \\
\hline
\end{tabular}

The total number of drugs prescribed in this study was 277 . The most common class of drugs prescribed being those of antidepressants group $102(36.82 \%)$ followed by antianxiety and antipsychotic group. Sertraline, lorazepam and olanzepine were the most commonly prescribed drugs in each of the aforementioned group respectively. The details of the observed drug use pattern in Major Depression is given in Table 2.

Total number of antidepressants prescribed was 102 (36.82\%). Out of antidepressant agents, Selective Serotonin Reuptake Inhibitors (SSRIs) were the most commonly prescribed drugs $70(68.62 \%)$ further details about the class of antidepressant and FDC is given in Table 3.

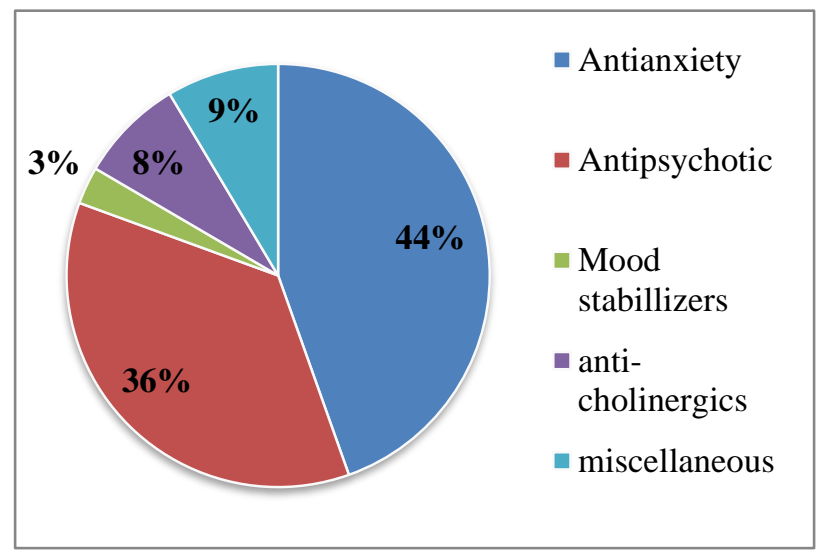

Figure 1: Concomitant medications in major depression.

The most commonly prescribed antidepressant was Sertraline in 35 (34.3\%) details in Table 2 and Figure 1. Most common concomitant medications in Major Depression was antianxiety drugs. The percentages of each group are depicted Figure 1. 
Table 2: Prescribing in major depression.

\begin{tabular}{|c|c|c|c|}
\hline Groups & Number (\%) & Agents & Number (\%) \\
\hline \multirow{6}{*}{ Antidepressants } & \multirow{6}{*}{$102(36.82 \%)$} & Sertraline & $35(12.63 \%)$ \\
\hline & & Fluoxetine & $28(10.10 \%)$ \\
\hline & & Escitalopram & $17(6.13 \%)$ \\
\hline & & Venlafaxine & $05(1.80 \%)$ \\
\hline & & Mirtazepine & $05(1.80 \%)$ \\
\hline & & Amitryptiline & $12(4.33 \%)$ \\
\hline \multirow{5}{*}{ Anti -anxiety } & \multirow{5}{*}{$78(28.15 \%)$} & Lorazepam & $28(10.10 \%)$ \\
\hline & & Clonazepam & $35(12.63 \%)$ \\
\hline & & Alprazolam & $04(1.44 \%)$ \\
\hline & & Chlordiazepoxide & $03(1.02 \%)$ \\
\hline & & Buspirone & $08(2.88 \%)$ \\
\hline \multirow{4}{*}{ Antipsychotics } & \multirow{4}{*}{$63(22.74 \%)$} & Olanzapine & $20(7.22 \%)$ \\
\hline & & Aripiprazole & $19(6.85 \%)$ \\
\hline & & Quetiapine & $19(6.85 \%)$ \\
\hline & & Risperidone & $05(1.80 \%)$ \\
\hline Mood stabilizers & $05(1.80 \%)$ & Oxcarbamazepine & $05(1.80 \%)$ \\
\hline Anti- cholinergic & $14(5.04 \%)$ & Trihexiphenidyl & $14(5.05 \%)$ \\
\hline \multirow{3}{*}{ Miscellaneous } & \multirow{3}{*}{$15(5.41 \%)$} & Amoxycillin & $04(1.44 \%)$ \\
\hline & & Iron preparation & $07(2.44 \%)$ \\
\hline & & B-complex & $04(1.44 \%)$ \\
\hline Total & $277(100 \%)$ & Total & $277(100 \%)$ \\
\hline
\end{tabular}

Table 3: Antidepressants use in M. depression.

\begin{tabular}{|ll|}
\hline Drugs & Number $(\%)$ \\
\hline $\begin{array}{l}\text { Number of } \\
\text { antidepressants } \\
\text { prescribed }\end{array}$ & $102(36.8 \%)$ \\
\hline SSRI & $70(68.6 \%)$ \\
\hline TCA & $20(19.6 \%)$ \\
\hline Atypical & $10(11.7 \%)$ \\
\hline $\begin{array}{l}\text { Most commonly } \\
\text { prescribed } \\
\text { antipsychotic- } \\
\text { Sertraline }\end{array}$ & $35(34.3 \%)$ \\
\hline FDCs & $\begin{array}{l}\text { Fluoxetine+Olanzapine }(20) \\
\text { Escitalopram+Clonazepam }(7)\end{array}$ \\
\hline
\end{tabular}

\section{DISCUSSION}

Female preponderance was observed in this study which was consistent with the similar study by Mishra et al. ${ }^{9}$ Amongst antidepressants prescribed SSRIs were the most commonly prescribed in 70 (68.62\%) followed by TCAs in $20(19.60 \%)$ and Atypical antidepressants in 10 $(11.76 \%)$ cases which is similar to study conducted by Ahmad et al. ${ }^{10}$ This is according to the current recommendations (APA and NICE) in the management of mood disorders. ${ }^{11,12}$ SSRIs are preferred because of safer adverse-effect profile and better compliance. MAO inhibitors were not prescribed. This could be because of cardiovascular risk and drug interactions. ${ }^{13}$ Most commonly prescribed SSRIs, TCA and Atypical antidepressant were Sertraline 35 (12.63\%), Amitriptyline $12(4.33 \%)$ and Venlafaxine5 $(1.8 \%)$ respectively details are given in Table 2. This is in accordance with Thakkar et al. In this study off label anti-psychotics were prescribed in $63(22.74 \%)$. This could be for associated psychotic symptoms and most common off label anti-psychotics was Olanzapine in $20(7.22 \%)$ Table 2. Benzodiazepines were co-prescribed in $78(76 \%)$ patients and most common was Clonazepam 35 (12.63\%). ${ }^{14-16}$ Details of the concomitant medications are given in Figure 1. Similar findings were observed by other investigators as well (Mohanta, Manavalan, Prabha, Prasanna). It was observed that 92 $(94.8 \%)$ patients were prescribed mono therapy (single antidepressant) and $05(5.15 \%)$ were prescribed a combination of two antidepressants (polypharmacy). This is comparable with Mishra et al.

\section{CONCLUSION}

Psychiatric disorders form an important public health priority as they affect an individual's overall health, quality of life and productivity. Hence, we undertook the present study to evaluate the prescribing patterns of hospital psychiatrists in indoor Major depression patients as per WHO criteria. Atypical antidepressants are still sparsely used in India. In contrary to the recommendations Polypharmacy is on rise in psychiatry. Off label use of antipsychotic drug was commonly observed. Further study will be required to see the changing trends in prescribing. 
Funding: No funding sources

Conflict of interest: None declared

Ethical approval: The study was approved by the Institutional Ethics Committee

\section{REFERENCES}

1. World Health Organization. The World Health Report 2001- Mental Health: New understanding, new hope (Internet). Geneva; 2001.

2. Math SB, Chandrashekar CR, Bhugra D. Psychiatric epidemiology in India. The Ind J Med Res (Internet). 2012 Nov 21);126(3):183-92.

3. Murthy R. Mental Health Programme in the $11^{\text {th }}$ Five year plan. The Indian Journal of Medical Research (Internet). 200711 (June):707-712.

4. Sharma P, Das S, Deshpande S. An estimate of the monthly cost of two major mental disorders in an Indian metropolis. Indian J Psychiatry. 2006;48:1438.

5. Thakkar KB, Jain MM, Billa G, Joshi A, Khobragade AA. A drug utilization study of psychotropic drugs prescribed in the psychiatry outpatient department of a tertiary care hospital. JCDR. 2013 Dec;7(12):2759.

6. Organisation for economic cooperation and development. OECD Policy brief - Mental health in OECD countries. Paris: OECD, 2008.

7. Tinsley JA, Shadid GE, Li H, Offord KP, Agerter DC. Psychotropic prescribing practices and educational needs: a survey of family physicians and psychiatrists. Gen Hosp Psychiat. 1998;20:360-7.

8. Bouhassira M, Allicar MP, Blachier C, Nouveau A, Rouillon F. Whichpatients receive antidepressants? A 'real world' telephone study. J Affective Disorders 1998;49:19-26.

9. Mishra A, Swain TR, Mohanty MA. Patterns of prescription and efficacy evaluation of antidepressants in a tertiary care teaching hospital in eastern India. Asian J Pharm Clin Res. 2012;5:19-22.

10. Ahmad F, Singh PP, Manoj, Kumar A, Gaur RK. Drug Prescribing pattern for major depressive psychosis patients in geriatric clinic of a teaching hospital in northern India. Int J Pharm Pharm Sci. 2013;5(2):26972.

11. Practice guideline for the treatment of patients with major depressive disorder. $3^{\text {rd }}$ Ed. Arlington (VA): American Psychiatric Association (APA). 2010:152.

12. NICE. Depression in adults (update)(CG90). National Institute for Health and Clinical Excellence. National Collaborating Centre for Mental Health; 2009.

13. Balon R, Mufti R, Arfken CL. A survey of prescribing practices for monoamineoxidase inhibitors. Psychiatric services (Washington, D. C.); 1999.

14. Furukawa TA, Streiner DL, Young LT. Is antidepressant-benzodiazepine combination therapy clinically more useful? a meta-analytic study. J Affect Disord. 2001;65:173-7.

15. Smith WT, Londborg PD, Glaudin V, Painter JR. Is extended clonazepam cotherapy of fluoxetine effective for outpatients with major depression?. J Affe Disorde. 2002 Aug 1;70(3):251-9.

16. Adli M, Rossius W, Bauer M. Olanzapine in the treatment of depressive disorders with psychotic symptoms. Nervenarzt. 1990;70:68-71.

Cite this article as: Thakare V, Dubey L.

Observational study of drug use pattern in indoor patients suffering from major depression admitted in psychiatry department of tertiary care teaching hospital. Int J Basic Clin Pharmacol 2018;7:1808-11. 